\title{
Inhaled corticosteroids and lower lung function decline in young children with cystic fibrosis
}

\author{
K. De Boeck*, F. Vermeulen*, S. Wanyama* and M. Thomas" ${ }^{\#}$, on behalf of the \\ members of the Belgian CF Registry
}

ABSTRACT: A recent American registry analysis in cystic fibrosis (CF) children showed less lung function decline after starting inhaled corticosteroid (ICS) use. We therefore examined the influence of ICS treatment on lung function in Belgian CF patients.

Data from patients $\geqslant 6$ yrs of age were eligible, provided entries on lung function, height and ICS use were available in two consecutive years. Data after oral steroid use or transplant were excluded.

852 subjects contributed data with 2,976 data pairs analysed, $44.9 \%$ concerning years of ICS use. Yearly \% predicted decline in forced expiratory volume in $1 \mathrm{~s}$ (FEV1) was $1.07 \%$ lower during ICS use $(p=0.001)$. Subgroup analysis for age revealed that the lower FEV 1 decline rate during ICS use was only statistically significant in children $6-12$ yrs of age $(2.56 \% ; p=0.0003)$. Baseline FEV 1 was lower by $5.89 \%(p<0.0001)$ in ICS users for all age groups combined, but there was no difference in baseline lung function in the children 6-12 yrs of age.

In 6-12-yr-old children with CF, baseline lung function was similar in ICS users and nonusers, but annualised FEV1 decline was $2.56 \%$ pred lower in ICS users. Our data therefore support recent American findings.

KEYWORDS: Cystic fibrosis, inhaled corticosteroids, lung function, registry

$\mathrm{n}$ national cystic fibrosis $(\mathrm{CF})$ registries that report on inhaled corticosteroid (ICS) use, the prescription rates vary from $21.9 \%$ in Australian children and $38.2 \%$ in Australian adults [1], and $>37.5 \%$ of subjects in the French CF registry [2], to $56 \%$ of patients in the Belgian CF registry [3]. This high use is in contrast with the absence of solid evidence for ICS efficacy in the treatment of CF lung disease [4-6].

Side-effects from ICS use include growth impairment. A minor effect on growth is indeed documented in patients with asthma [7]. As a group, children with $\mathrm{CF}$ already have decreased growth velocity $[8,9]$ and this could be worsened by ICS treatment. In addition, there is evidence that catch-up of growth after treatment with alternate-day oral steroids or ICS may not fully occur in patients with CF $[10,11]$.

Despite this absence of evidence, physicians continue to prescribe ICSs to many CF patients. A recent analysis of the $\mathrm{CF}$ registry data from
North America, however, concluded that ICS therapy in children with CF was associated with a significant reduction in the rate of decline of forced expiratory volume in $1 \mathrm{~s}$ (FEV1). This came at the cost of some decrease in linear growth and an increase in insulin/oral hypoglycaemic drug use [12]. In the latter study, baseline lung function was worse in patients starting treatment with ICS.

Because of continuing high use and conflicting evidence, further analysis of positive and negative effects of ICS use in CF patients is warranted. In the Belgian CF Registry, ICS use is declared in $56 \%$ of patients [3]. Exactly because of this high ICS use, a randomised controlled trial has a high risk of failure because of insufficient patient recruitment [5]. In such a situation, analysis of real-life data via patient registries can be a valid source of information [12]. The aim of this study was, therefore, to evaluate the effect of ICS use on the evolution of lung function, growth and insulin use in Belgian CF patients.

\section{AFFILIATIONS}

*Paediatric Pulmonology, University of Leuven, Leuven, and ${ }^{\#}$ Scientific Institute of Public Health, Brussels, Belgium.

\section{CORRESPONDENCE}

K. De Boeck Paediatric Pulmonology University of Leuven Herestraat 49 Leuven 3000 Belgium E-mail: christiane.deboeck@ uz.kuleuven.ac.be

Received:

May 182010 Accepted after revision: Aug 112010

First published online: Nov 112010 


\section{METHODS}

This was a retrospective analysis, based on data obtained from the Belgian Cystic Fibrosis Registry (BMR-RBM) for the years 1998-2007. The Belgian CF Registry was established in 1998. Since 2006, the registry has been hosted, administered and analysed by the Scientific Institute of Public Health (Brussels, Belgium), a governmental institution for public health research and epidemiology. The 2007 patient report contains data on 1,057 patients. Based on an estimated CF prevalence of 1 in 3,000 in Belgium, the BMR-RBM is considered to cover $>95 \%$ of all CF subjects in the country.

The registry data are collected annually according to strict definitions. For height (stadiometer with $0.1-\mathrm{cm}$ precision) and weight (scale with $0.1-\mathrm{kg}$ precision), data from the last outpatient visit of the year are used. For FEV1 and forced vital capacity (FVC), the last value of the year measured prebronchodilator is reported in litres (precise to two decimal places). Date and height on that occasion is specified. Inhaled therapies are recorded annually as absent or present (e.g. ICS yes/no and bronchodilators yes/no).

\section{Data selection}

To evaluate the effect of ICS use on lung function evolution, data from patients $\geqslant 6$ yrs of age were eligible, provided entries on lung function, height and ICS use were available in at least two consecutive years. All data after oral steroid use and data from transplanted patients were excluded. At least two consecutive annual observations were available in 1,160 out of the 1,265 CF patients ever recorded in the CF registry. Were excluded from analysis: 135 patients $<6$ yrs of age in 2007; 38 subjects $\geqslant 6$ yrs of age without two annual observations in consecutive years; and 135 subjects with onset of oral steroid therapy in the first or second year of registry entry. To calculate the \% predicted FVC and FEV1, the equations of WANG et al. [13] (6-17 yrs of age) and HANKINSON et al. [14] ( $\geqslant 18$ yrs of age) were used. The difference between the values was calculated as year 2 minus year 1 . ICS use in the second year was taken to assign the data set to ICS treatment or not. Using the exact dates of measurements, adjustments were made to obtain the rate of change over $1 \mathrm{yr}$. If possible, several data pairs were used per patient. Thus, 852 subjects contributed data (454 males and 398 females), with
2,976 data pairs analysed, $44.9 \%$ concerning years of ICS use. The following age categories were used: 6-12, 13-17 and $\geqslant 18$ yrs.

To evaluate the effect of ICS use on growth, only the age categories 6-12 and 13-17 yrs were considered. Height was expressed as Z-score based on Centers for Disease Control growth charts [15]. Changes between consecutive years were annualised using the exact dates of measurements.

\section{Statistical methodology}

Descriptive data of the study population are presented as mean \pm SD. Normality of the data was checked using the Kolmogorov-Smirnov test using the SAS R Univariate procedure (SAS Institute, Cary, NC, USA). The independent twosample t-test was used to compare differences between ICS and non-ICS years for normally distributed data. Categorical variables were analysed using the Chi-squared test. Though conservative, the Bonferroni correction method was used to address the problem of subgroup analyses (five subanalyses for FEV1 and three for growth), so as to maintain the familywise error rate to 0.05 [16]. In all cases, two-sided tests were used. To obtain population estimates for inference, a longitudinal data analysis was done by fitting multiple linear regression models for the response against predictors in the Mixed Procedure in SAS R version 9.1.3. The least squares means were obtained for each response as estimates for the average yearly change in the FEV1\% pred and height Z-score.

\section{RESULTS \\ Lung function decline}

Baseline lung function and annualised FEV1 decline in different age categories are depicted in table 1. Yearly decline in FEV1 was lower during ICS use $(\mathrm{p}=0.001)$, and was seen in males (difference $0.95 \% ; p=0.028$ ) and in females (difference $1.20 \% ; p=0.015$ ). Subgroup analysis for age revealed that the significantly lower rate of decline in years of ICS use was only seen in children $6-12$ yrs of age $(p=0.0003)$. For all age groups combined, baseline FEV1 was lower in ICS users by $5.89 \%$ $(p<0.0001)$. However, there was no difference in baseline FEV1 in the children 6-12 yrs of age, in whom the difference in FEV1 decline was largest and amounted to $2.56 \% \mathrm{pred} \cdot \mathrm{yr}^{-1}$. With

\begin{tabular}{|c|c|c|c|c|c|c|c|c|c|}
\hline \multirow[t]{2}{*}{ Age range } & \multirow[t]{2}{*}{ ICS use } & \multirow[t]{2}{*}{ Subjects $n$} & \multirow{2}{*}{$\begin{array}{l}\text { Years with } \\
\text { ICS use \% }\end{array}$} & \multicolumn{3}{|c|}{ Yearly FEV 1 change $\%$ pred } & \multicolumn{3}{|c|}{ Baseline FEV $1 \%$ pred } \\
\hline & & & & Change & Difference & p-value & Baseline & Difference & $p$-value \\
\hline $13-17$ yrs & $\begin{array}{l}\text { No ICS } \\
\text { ICS }\end{array}$ & $\begin{array}{l}331 \\
276\end{array}$ & 45.5 & $\begin{array}{l}-1.71 \pm 9.34 \\
-1.02 \pm 9.39\end{array}$ & 0.69 & 0.3624 & $\begin{array}{l}84.1 \pm 19.5 \\
79.6 \pm 21.5\end{array}$ & 4.43 & 0.0152 \\
\hline$\geqslant 18$ yrs & $\begin{array}{l}\text { No ICS } \\
\text { ICS }\end{array}$ & $\begin{array}{l}758 \\
731\end{array}$ & 49.1 & $\begin{array}{l}-0.90 \pm 8.21 \\
-0.43 \pm 7.26\end{array}$ & 0.46 & 0.2487 & $\begin{array}{l}66.7 \pm 21.2 \\
61.6 \pm 21.1\end{array}$ & 5.05 & $<0.0001$ \\
\hline Overall & $\begin{array}{l}\text { No ICS } \\
\text { ICS }\end{array}$ & $\begin{array}{l}1638 \\
1338\end{array}$ & 44.9 & $\begin{array}{l}-1.22 \pm 9.17 \\
-0.15 \pm 8.50\end{array}$ & 1.07 & 0.001 & $\begin{array}{l}79.1 \pm 22.6 \\
73.2 \pm 24.0\end{array}$ & 5.89 & $<0.0001$ \\
\hline
\end{tabular}

Data are presented as mean \pm SD, unless othewise stated. Global analysis and analysis in age categories $6-12,13-17$ and $\geqslant 18$ yrs. $\%$ pred: $\%$ predicted. 
TABLE 2 Yearly change in forced expiratory volume in $1 \mathrm{~s}$ (FEV 1 ) according to use of other medications

\begin{tabular}{|c|c|c|c|c|c|c|c|c|}
\hline Medication & Medication use & Subjects $\mathrm{n}$ & Use \% & Yearly change & Difference & p-value & OR $(95 \% \mathrm{Cl})$ & p-value \\
\hline \multirow[t]{2}{*}{ Inhaled antibiotics } & No & 972 & \multirow{2}{*}{67.4} & $-0.99 \pm 9.5$ & \multirow{2}{*}{0.37} & \multirow{2}{*}{0.3012} & \multirow{2}{*}{$2.5(2.3-2.8)$} & \multirow{2}{*}{$<0.0001$} \\
\hline & Yes & 2004 & & $-0.62 \pm 8.5$ & & & & \\
\hline Bronchodilators & No & 1093 & 63.3 & $-0.91 \pm 9.2$ & 0.27 & 0.4387 & $7.4(6.6-8.4)$ & $<0.0001$ \\
\hline rhDNAse & Yes & 1864 & 62.6 & $-0.93 \pm 8.8$ & 0.52 & 0.1250 & $1.1(1.0-1.2)$ & 0.0131 \\
\hline \multirow[t]{2}{*}{ Mucolytics } & No & 921 & \multirow{2}{*}{69.0} & $-0.81 \pm 8.7$ & \multirow{2}{*}{0.09} & \multirow{2}{*}{0.7845} & \multirow{2}{*}{$1.7(1.5-1.8)$} & \multirow{2}{*}{$<0.0001$} \\
\hline & Yes & 2055 & & $-0.71 \pm 9.0$ & & & & \\
\hline
\end{tabular}

Data are presented as mean \pm SD, unless otherwise stated. \% pred: \% predicted; ICS: inhaled corticosteroid; rhDNAse: recombinant human deoxyribonuclease.

increasing age, the use of ICS increased; the difference in baseline lung function between ICS users and nonusers also increased, but the difference in yearly FEV1 decline between the two groups decreased and was not statistically significant beyond the youngest age group.

The proportion of observations with a yearly decline in FEV1 $>5 \%$ pred was lower in ICS treatment years (26 versus 33\%; $\mathrm{p}=0.0003)$. Patients with higher baseline FEV1 ( $\geqslant 90 \%$ pred $)$ had significantly higher annual rates of decline: $1.9 \%$ pred compared with $0.4 \%$ pred in the group with FEV1 $<90 \%$ pred $(\mathrm{p}=0.0084)$.

There was no difference in yearly decline in FEV1 between subjects with and without bronchodilator use $(p=0.439)$, even though bronchodilator users had significantly lower baseline lung function by $10.2 \%$ pred $(\mathrm{p}<0.0001)$ (table 2$)$. Although there was an association between ICS use and use of bronchodilators (OR 7.4, 95\% CI 6.6-8.4; $\mathrm{p}<0.001$ by Chisquared test), no significant interaction was found between ICS and bronchodilator use after adjusting for patient's age and baseline lung function. The results for other inhaled medications, namely antibiotics, recombinant human deoxyribonuclease and mucolytics, were quite similar (table 2).

The effect of ICS use on FEV1 decline was seen in patients with $(\mathrm{p}=0.0339)$ and without $(\mathrm{p}=0.0025)$ chronic Pseudomonas aeruginosa colonisation. Colonised patients were more likely to use ICS than the noncolonised patients (OR 1.19, 95\% CI $1.01-1.41 ; \mathrm{p}=0.0414)$. This is concordant with the fact that $P$. aeruginosa colonisation, as well as ICS use, increases with age.

\section{Effect on growth and insulin use}

There was no overall effect of ICS use on height $(p=0.2010)$ after adjusting for patient age and gender. Only in the age group 6-12 years, was the yearly growth significantly lower with ICS use. But this effect was small (4 mm per year) only amounting to $0.04 \mathrm{Z}$-score (table 3).

Insulin use was slightly higher in ICS use years (OR 1.3, 95\% CI 0.99-1.69), but this difference was not statistically significant $(p=0.0598)$. On the whole, insulin use was reported in $7.8 \%$ of the years analysed.

\section{DISCUSSION}

Inhaled corticosteroids continue to be prescribed to many patients with $\mathrm{CF}$, although guidelines do not advocate their use [6]. The current analysis confirms the findings by REN et al. [12] that ICS use is associated with a lower yearly decline in lung function in children 6-12 yrs of age. Use of ICS thus decreased the rate of decline in young children before major loss in lung function occurred. These registry data thus pose the important clinical question of whether anti-inflammatory therapy with ICS can prevent loss of lung function in young CF

TABLE 3 Yearly height change and in Z-score according to inhaled corticosteroid (ICS) use between 6 and 17 yrs of age

\begin{tabular}{|c|c|c|c|c|c|}
\hline Age category & ICS use & Subjects n & Yearly growth $\mathrm{cm}$ & Yearly change in height Z-score & p-value \\
\hline $6-12$ yrs & No ICS & 542 & $5.4 \pm 1.6$ & $-0.05 \pm 0.25$ & 0.0190 \\
\hline \multirow[t]{2}{*}{$13-17$ yrs } & No ICS & 307 & $3.7 \pm 2.9$ & $0.01 \pm 0.28$ & \multirow{2}{*}{0.3167} \\
\hline & ICS & 250 & $3.6 \pm 2.8$ & $0.03 \pm 0.23$ & \\
\hline Overall & No ICS & 849 & $4.8 \pm 2.3$ & $-0.03 \pm 0.26$ & 0.4189 \\
\hline
\end{tabular}

Data are presented as mean $\pm \mathrm{SD}$, unless otherwise stated. 
patients with preserved lung function. This question needs to be settled by a properly designed randomised controlled trial.

As CF newborn screening is being instituted around the world, the focus of research must move to younger children. It has been shown that lung damage occurs early in life. At the age of $5 \mathrm{yrs}$, and despite good nutritional status and maintained lung function, $56 \%$ of children diagnosed by newborn screening have bronchiectasis [17]. Inflammation in the lung is present early and out of proportion with the degree of infection [18]. Therefore, it is certainly biologically plausible that the use of ICS is associated with a slower rate of lung function decline.

ICSs are the standard treatment of the eosinophilic inflammation in asthma, but their effect on the neutrophilic inflammation associated with CF lung disease has been shown [19]. Other treatments aimed at decreasing neutrophilic inflammation have also been shown to benefit patients with CF, such as the use of azithromycin in subjects with [20] and without [21] chronic $P$. aeruginosa infection. Also, the nonsteroidal anti-inflammatory drug ibuprofen, taken for 4 yrs, decreased lung disease progression in CF patients with mild lung disease in a doubleblind trial [22]. The same beneficial effect of long-term ibuprofen treatment in children and adolescents with mild lung disease was subsquently demonstrated using observational data from the Cystic Fibrosis Foundation Patient Registry [23].

Previous attempts to set up large scale-studies proving the efficacy of ICS have failed to include sufficient numbers of subjects, hence the well known ICS withdrawal study [5]. With the current surge in CF research and many competing trials, including trials with drugs targetting the basic defect of the disease, a clinical study with a freely prescribed drug faces stiff competition. Since the effect size is marked and appears most in the youngest age group, a study in this age category is warranted, and would coincide with the need for better treatments in young and relatively healthy subjects. In the American registry data, the mean age when ICS were started was 11 yrs [12]. This suggests that steroid-naïve patients $<11$ yrs of age must be available. The assets of this potential "low-hanging fruit", the name used for drugs licensed for indications other than $\mathrm{CF}$, are multiple: the effect size of the intervention seems clinically relevant $(>2 \%$ difference in rate of FEV1 decline); the drug is cheap; and the side effects in the low-to-medium dose range are limited and well known. For study design, a randomised, double-blind, placebo-controlled trial in children 6-12 yrs of age is the best option. Choosing FEV1 decline as the primary outcome parameter could be problematic, given the low mean rate of FEV1 decline in that age category. To show a change in slope of decline a long study duration is needed [24]. Using the data from the Belgian CF registry with a mean FEV1 decline of $1.37 \%$ pred in 6-12-yr-old children not treated with ICS, a between-patient variance of the slope of 104.65 and a within-patient variance of 10.35 , and taking as the hypothesis a $1 \%$ pred difference in the slope of decline, plus a study design with four FEV1 measurements per year for 4 yrs, then 242 patients per treatment arm are needed. Increasing the treatment effect to $2 \%$ change in slope per year decreases the number needed per treatment arm to 61 subjects; but given the low decline rate, such a large treatment effect is unlikely in a prospective study. These estimates are similar to calculations performed in the excellent review article by COREY
[24]. More sensitive outcome paramaters are indeed badly needed in the young age group. Lung clearance index has been successfully used as primary outcome parameter in a small study exploring the usefulness of hypertonic saline in young $\mathrm{CF}$ children with near-normal lung function [25]. More information on long-term evolution of lung clearance index in CF children is needed. Any planned study should, however, not only establish the influence of ICS on lung function evolution and pulmonary exacerbations, but also assess the effect of ICS on CF airway inflammation evaluated via induced sputum or bronchoalveolar lavage.

We did not restrict our analysis to the paediatric age group and noted that the benefit from ICS was absent in the adult group. It is again biologically plausible that ICS would decrease airway inflammation in young, relatively healthy subjects, and that the effect of the drug is not seen in older subjects with lower lung function and probably a larger burden of bacterial infection. An alternative explanation is that the drug target is not reached in patients with significant infection and mucus impaction. The effect of ibuprofen, a drug taken orally, on lung function decline in patients with mild lung disease [22, 23] is striking and makes the latter explanation less likely. A positive effect may be present in children $<6$ yrs of age, but since a widely applicable outcome measure to evaluate lung disease severity is not available in that age group, there are no conclusions possible from our data set.

Registry data are not comparable to the results of clinical trials. Further limitations of the current data collection are that we have no information on the specific drug, the dose of the drug used or the association with long acting bronchodilating agents (LABA; the latter not being recorded). Recent in vitro data suggest that salmeterol may stabilise the CF transmembrane conductance regulator protein at the cell surface and, therefore, the positive effect in the ICS group could be mediated via a LABA effect [26]. However, analysis of the effect of bronchodilator use on FEV1 decline did not show a positive effect.

In conclusion, analysis of Belgian CF registry data confirms the findings in the American Registry that ICS use is associated with a decrease in lung function decline in children 6-12 yrs of age. A positive effect from ICS treatment in these children is possible, especially in the face of the knowledge that inflammation in the lung starts early. Only an adequately powered, randomised, placebo-controlled trial in this age category can definitively settle the argument.

\section{STATEMENT OF INTEREST}

None declared.

\section{ACKNOWLEDGEMENTS}

We thank the patients, parents, and CF physicians and their teams who contributed data to the Belgian CF registry. We thank H. Jansen, coordinator of the Belgian CF registry (G. Casimir, F. De Baets, K. De Boeck, P. Lebecque, A. Malfroot, J.P. Sacré and L. Van Schil), and V. Van Casteren, who is responsible for the CF registry programme (Scientific Institute of Public Health, Brussels, Belgium).

\section{REFERENCES}

1 Cystic fibrosis in Australia. 10th Annual Report from the Australian Cystic Fibrosis Data Registry. www.cysticfibrosis.org. 
au/pdf/Cystic_Fibrosis_in_Australia_2007.pdf Date last updated: 2007.

2 Vaincre la Mucoviscidose. Rapport annuel 2006 [French CF Patient and Parent Organisation. CF Registry Annual Report 2006]. www. vaincrelamuco.org/e_upload/pdf/rapport_annuel_2006.pdf Date last updated: 2006.

3 BMR-RBM 2007. Annual Data Report, Belgium. Cystic Fibrosis Patient Registry. www.wiv-isp.be/epidemio/epinl/index20.htm Date last updated: March 23, 2010.

4 Dezateux C, Walters S, Balfour-Lynn I. Inhaled corticosteroids for cystic fibrosis. Cochrane Database Syst Rev 2000; 2: CD001915.

5 Balfour-Lynn IM, Lees B, Hall P, et al. Multicenter randomized controlled trial of withdrawal of inhaled corticosteroids in cystic fibrosis. Am J Respir Crit Care Med 2006; 173: 1356-1362.

6 Flume PA, O'Sullivan BP, Robinson KA, et al. Cystic fibrosis pulmonary guidelines: chronic medications for maintenance of lung health. Am J Respir Crit Care Med 2007; 176: 957-969.

7 Long-term effects of budesonide or nedocromil in children with asthma. The Childhood Asthma Management Program Research Group. N Engl J Med 2000; 343: 1054-1063.

8 Assael BM, Casazza G, Iansa P, et al. Growth and long-term lung function in cystic fibrosis: a longitudinal study of patients diagnosed by neonatal screening. Pediatr Pulmonol 2009; 44: 209-215.

9 Switzer M, Rice J, Rice M, et al. Insulin-like growth factor-I levels predict weight, height and protein catabolism in children and adolescents with cystic fibrosis. J Pediatr Endocrinol Metab 2009; 22: 417-424.

10 Lai HC, FitzSimmons SC, Allen DB, et al. Risk of persistent growth impairment after alternate-day prednisone treatment in children with cystic fibrosis. N Engl J Med 2000; 342: 851-859.

11 De Boeck K, De Baets F, Malfroot A, et al. Do inhaled corticosteroids impair long-term growth in prepubertal cystic fibrosis patients? Eur J Pediatr 2007; 166: 23-28.

12 Ren CL, Pasta DJ, Rasouliyan L, et al. Relationship between inhaled corticosteroid therapy and rate of lung function decline in children with cystic fibrosis. J Pediatr 2008; 153: 746-751.

13 Wang X, Dockery DW, Wypij D, et al. Pulmonary function between 6 and 18 years of age. Pediatr Pulmonol 1993; 15: 75-88.
14 Hankinson JL, Odencrantz JR, Fedan KB. Spirometric reference values from a sample of the general U.S. population. Am J Respir Crit Care Med 1999; 159: 179-187.

15 Kuczmarski RJ, Ogden CL, Guo SS, et al. 2000 CDC Growth Charts for the United States: methods and development. Vital Health Stat 2002; 11: 1-190.

16 Simes JR. An improved Bonferroni procedure for multiple test of significance. Biometrika 1986; 73: 751-754.

17 Stick SM, Brennan S, Murray C, et al. Bronchiectasis in infants and preschool children diagnosed with cystic fibrosis after newborn screening. J Pediatr 2009; 155:623-628 e621.

18 Muhlebach MS, Stewart PW, Leigh MW, et al. Quantitation of inflammatory responses to bacteria in young cystic fibrosis and control patients. Am J Respir Crit Care Med 1999; 160: 186-191.

19 Wojtczak HA, Kerby GS, Wagener JS, et al. Beclomethasone diproprionate reduced airway inflammation without adrenal suppression in young children with cystic fibrosis: a pilot study. Pediatr Pulmonol 2001; 32: 293-302.

20 Saiman L, Marshall BC, Mayer-Hamblett N, et al. Azithromycin in patients with cystic fibrosis chronically infected with Pseudomonas aeruginosa: a randomized controlled trial. JAMA 2003; 290: 1749-1756.

21 Clement A, Tamalet A, Leroux $\mathrm{E}$, et al. Long term effects of azithromycin in patients with cystic fibrosis: A double blind, placebo controlled trial. Thorax 2006; 61: 895-902.

22 Konstan MW, Byard PJ, Hoppel CL, et al. Effect of high-dose ibuprofen in patients with cystic fibrosis. N Engl J Med 1995; 332: 848-854.

23 Konstan MW, Schluchter MD, Xue W, et al. Clinical use of Ibuprofen is associated with slower FEV1 decline in children with cystic fibrosis. Am J Respir Crit Care Med 2007; 176: 1084-1089.

24 Corey M. Power considerations for studies of lung function in cystic fibrosis. Proc Am Thorac Soc 2007; 4: 334-337.

25 Amin R, Subbarao P, Jabar A, et al. Hypertonic saline improves the LCI in paediatric patients with CF with normal lung function. Thorax, 65: 379-383.

26 Delavoie F, Molinari M, Milliot M, et al. Salmeterol restores secretory functions in cystic fibrosis airway submucosal gland serous cells. Am J Respir Cell Mol Biol 2009; 40: 388-397. 